\title{
KEY FACTORS AND BARRIERS OF BUSINESS INTELLIGENCE IMPLEMENTATION
}

\author{
Peter Mesároš $\check{s}^{*}$ Štefan Čarnický ${ }^{* *} \&$ Tomáš Mandičák $k^{* * *}$
}

The business environment is constantly changing and becoming more complex and difficult. Enterprises are under pressure, which forces them to react quickly to changing conditions and be innovative in the field in which they work. Such activities require businesses to be more flexible and to take frequent and quick strategic, tactical and operational decisions, some of which are very complex. Receipt of such decisions may require significant amounts of data, information and knowledge. Processing within the required decisions must be made quickly, often in real time and usually requires some automated support. Since the early 21st century, ICT based solutions called Business Intelligence (BI) become an important decision support tool and an integral part of the daily work of managers, analysts and executives across the enterprise. Adoption and use of BI are affected by several factors. The paper presents the results of studies which show the factors for the successful implementation and use of BI. The contribution also points to the influence of individual factors for effective implementation and use of BI and also the impact on the efficient management of processes in the company.

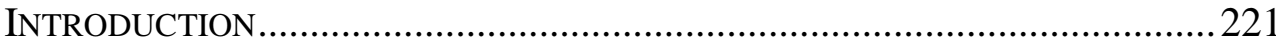

I. BUSINESS INTELLIGENCE AND APPROACHES TO BI ............................... 221

A. Gradual Building of Data Marketplaces Approach ................ 222

B. Single Construction Approach........................................... 223

C. Incremental Approach ..................................................... 223

II. BARRIERS OF IMPLEMENTATION FOR EFFECTIVE USE OF BI ................. 224 III. IDENTIFICATION AND ANALYSIS OF KEY SUCCESS FACTORS OF IMPLEMENTATION AND USE OF BUSINESS INTELLIGENCE .........................226

\footnotetext{
* Peter Mesároš, Faculty of Civil Engineering, Technical University of Košice, Slovakia. Research fields: ICT in Business, Business Intelligence, Knowledge Management, Economics in Construction. ** Štefan Čarnický, University of Economics in Bratislava, Slovakia. Research fields: Information Systems, ICT in Business, Business Intelligence, Knowledge Management.

${ }^{* * *}$ Tomáš Mandičák, Faculty of Civil Engineering, Technical University of Košice, Slovakia. Research fields: Information Management, ICT in Business,

The paper presents partial results of the research project VEGA No. 1/0562/14 "The impact of Business Intelligence tools on corporate performance".

The paper presents the results of the project "Identification of key competencies of university students for the needs of knowledge society development in Slovakia", which is supported by the Ministry of Education, Science, Research and Sport of the Slovak Republic in supplying incentives for research and development from the state budget in accordance with Act no. 185/2009 Z. z. on incentives for research and development and on supplementing Act. 595/2003 Z. z. Income Tax, as amended, by Act no. 40/2011 Z. z.
} 
CONCLUSION

\section{INTRODUCTION}

To ensure that various obstacles and risks which are associated with BI would be resolved, it would be very important to identify and specifically to manage and exploit the key success factors for business intelligence (BI) solutions. Many studies show that BI is important for the effective management of business processes. It does not matter what is enterprise and in what areas operates. These BI solutions can be used in various fields. In order to BI success, it is essential to ensure smooth implementation of the BI. For the successful implementation, use of BI is necessary to know these BI success factors. For efficient use of BI is essential to know how the individual factors affect the implementation and use of BI solutions.

\section{BUSINESS INTELLIGENCE AND APPROACHES TO BI}

Business intelligence systems, which are designed to improve decisionmaking in enterprises, became an important part of management in recent years. BI system presents a complex task, technology and applications of information systems which strongly support analytical and planning activities of enterprises and organizations. They are built on the principle of multidimensionality by which we understand the opportunity to look at the reality from several possible perspectives. According to Gartner Group survey, BI is implemented in nearly $80 \%$ of companies in the U.S. and 50\% of companies in Europe. These relatively high percentages of BI extensions are mainly based on their effects on business success and the company's performance.

Under the BI concept, we understand all processes and activities from strategy formulation through BI project planning, custom design to operate BI applications and related methods, data, tools and finally the application software. Examples of BI solutions can be financial analytic applications, including all their data and technology components and all activities associated with their creation and operation. BI solutions need to be based on the complex task of management and design, with a complex design and development tools and the resulting applications.

Solving problems requires extensive BI complex management and analysis activities, both at the management system IS/ICT, as well as in one of the BI project. Development of BI applications and everything that comes with it is very difficult and long-term task that brings with it except for solutions to technical problems, the necessary solution for the organization 
and personnel. This is the introduction of a new information system, which is larger than any project and cannot be done without relatively precise rules and procedures for the planning, design and operation.

At present, can come across three basic approaches to BI. These approaches are largely dependent on the selected and exploited BI architecture. In examining approaches to BI, we start with the definitions of these approaches, which present the authors O. Novotny et al.. ${ }^{1}$ Like the authors we distinguish three basic approaches to BI:

- gradual building data marketplace based on the architecture independent data marketplace,

- single approach to build the overall solution based on consolidated data warehouse architecture,

- incremental approach based on consolidated data warehouse architecture.

\section{A. Gradual Building of Data Marketplaces Approach}

It is the oldest historical approach to BI. The concept of architecture independent data marketplaces introduced in the eighties Ralph Kimball.

Main advantages of the gradual building data marketplaces are relatively rapid development of solutions that are usually delivered within a short time period of 3-6 months and the financial constraints of the project, which gives good financial control and monitoring ROI. Analytical needs of individual departments are addressed and met in the fastest possible time. Individual applications that are built around data marketplace are providing users with all information necessary for their analytical work. So that users do not have to navigate between different components of the overall solution and BI questions while making it easier to databases. Data marketplaces keeping detailed and aggregated data allow users to quickly break the aggregated reports on the details.

This approach has, however, several disadvantages and risks. This approach requires greater efforts to ensure the overall integration of BI data layer. The problem is integration layer commonly used dimensional scales, which are actually integrations solutions. Failing integration of the total solution may lose the ability to interpret the fact consolidated.

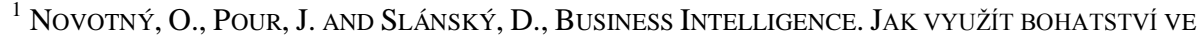
VAŠICH DATECH (Praha, Grada Publishing. ISBN 80-247-1094-3, 2005).
} 


\section{B. Single Construction Approach}

This approach compared with the previous approach of gradual building data marketplaces is associated with consolidated data warehouse architecture.

This approach is compared with the previous approach in several ways. Consolidated data warehouse architecture is flexible enough to be integrated to support demanding analytical tasks require not only aggregate but also detailed data. Data warehouse completely stored data make it easy to build another data marketplaces for the needs of different users. In addition to supporting forms of dimensional data warehouse directly supports the development of specialized data stores in another form, such as data mining. The big advantage of this approach is that data warehouse provides the ability to consolidated report and the fact that there is no duplication of BI components. Data stored in a data warehouse in this approach can be applied to other types of analytical tasks that they were originally intended.

On the other hand, this approach has some disadvantages. Building a total solution based on consolidated data warehouse architecture takes longer and is more expensive than the previous approach. This is particularly the initial phases of the solution. In this approach, a relatively high risk of changes exists in source systems or user requirements. During the implementation of analytical solutions given more time developing solutions to the financial effect of the solutions can be obtained much later after the start of the project compared with the previous approach. Moreover, it is impossible to keep track return on investment. Direct access from the detailed to aggregated data is technologically demanding because they must pass between the database layer of BI solutions.

\section{Incremental Approach}

Incremental approach is the youngest approach. This approach is the same as the previous approach, combined with consolidated data warehouse architecture. Currently, the incremental approach is the most popular in practice and logically combines the advantages of both previous approaches.

This approach has several advantages. Individual solutions projects (increments) are developed gradually and in a relatively short time, which allows you to quickly respond to key business needs. In the event of changes in the enterprise, there is scope to adapt the concept of building solutions. Development projects (increments) are relatively short (3-6 months) and financial requirements for projects are limited. This allows you to perform a good financial control and track return on investment. 
Advantage also eliminates duplication of BI components. This approach with proper project management and compliance solution concepts leads to a gradual build-up single, integrated platform for all analytical applications company.

Incremental approach has also disadvantages and risks. Creation of the overall concept at the beginning of the project requires a lot of attention and some time, as determined by the total form BI solutions. In this analysis phase, it is also very important the support of senior management of the enterprise, without which this approach cannot be used.

\section{BARRIERS OF IMPLEMENTATION FOR EFFECTIVE USE OF BI}

The application of BI systems in business practice is associated not only with more advantages and benefits, but on the other hand, it also brings certain barriers, problems and risks. During the design process, implementation and use of BI solutions, businesses can run into many problems and complications that will need to be resolved. Not only technology plays a key role, but above all factors, such as people, processes, management style and culture of the organization, are also important. These factors often represent a big problem and can disrupt or prevent attempts and efforts of implementing effective BI solutions in organizations.

J. Pour ${ }^{2}$ formulated three key areas of the current problems of implementation of BI systems in practice:

- Insufficient qualifying preparedness and related lack of interest from the user community.

- Doubtful quality of source data, which simultaneously describes as the most common cause of failure of BI projects.

- The assumption that the company and its departments will accept changes in management style organizations that BI systems and their application in practice are requiring.

Eckerson $^{3}$ identifies the major barriers to BI in one of his studies. $\mathrm{He}$ divides the barriers to $\mathrm{BI}$ solutions for $\mathrm{BI}$ implementation barriers and barriers of using BI. The results of the author's research in which more than 650 collaborating organizations were participating, are given in Table 1 . Respondents are considered as the most serious obstacle to the implementation of $\mathrm{BI}$ in the enterprise time which is necessary for the

\footnotetext{
${ }^{2}$ Pour, J., Faktoryúspěšnosti Business Intelligence - užiti a řešení, 1 SYSTÉMOVÁ InTEGRACE 377-388 (ISSN 1210-9479, 2005).

${ }^{3}$ Eckerson, W., Data Quality and the Bottom Line: Achieving Business Success through a Commitment to High Quality Data (2002). Available at http://download.101com.com/pub/tdwi/Files/DQReport.pdf.
} 
introduction and acceptance of BI tools and overall process complexity, respectively its intensity (42\%). Preference of other available tools (e.g. MS Excel) instead of BI tools as well as dubious quality of source data is perceived by $30 \%$ of survey participants as the most significant barrier to effective use of BI.

Table 1 Barriers to Implementation and Use of Business Intelligence (Eckerson, 2002)

\begin{tabular}{cl}
\hline Barriers to implementation of Business Intelligence & $\mathbf{( \% )}$ \\
- difficulty and time needed to learn the BI tools & $42 \%$ \\
- the cost of obtaining a license BI & $34 \%$ \\
- lack of interest on the part of managers & $26 \%$ \\
- costs necessary to support and training system users & $26 \%$ \\
- lack of interest from users solutions & $24 \%$ \\
Barriers of using Business Intelligence & $19 \%$ \\
- users prefer other tools or methods & $\mathbf{( \% )}$ \\
- incorrect data & $30 \%$ \\
- too complex BI tools & $30 \%$ \\
- laggish response time of the system to user requirements & $27 \%$ \\
- too many reports and program files & $26 \%$ \\
- insufficient functional capabilities of the system & $26 \%$ \\
\hline
\end{tabular}

Some authors ${ }^{4,5}$ emphasized that the problems and barriers to successful implementation of BI solutions are not purely of technical nature (for example, questionable quality of the source data architecture, BI tools), but in many cases successful BI efforts of businesses are threatened namely by the social factors such as corporate policy, corporate culture and communication. Successful BI projects are usually the result of the right combination of the three elements of success - people, technology and processes. Thus, the authors propose to develop and follow a BI strategy, which consists of three components, respectively sub-strategies:

- corporate strategy, which aims to ensure consistency between BI efforts and processes and objectives of the organization as a whole, thus ensuring increased efficiency of business processes; culture;

- organizational strategy relating to the organization and corporate

- technology strategy, which aims to develop adequate technology

\footnotetext{
${ }^{4}$ Sabherwal, R. ANd BeCERra-Fernandez, I., Business Intelligence: Practices, TeChnologies, AND Management (New Jersey, Wiley Publishing. ISBN 978-0- 470-46170-9, 2010).

${ }^{5}$ Boyer, J. AND ET AL., Business InTELligence Strategy: A Practical Guide for ACHiEving Business INTELLIGENCE EXCELLENCE (Ketchum, MC Press. ISBN 978-1-58347-362-7, 2010).
} 
infrastructure solutions and enables the achievement of increasing the efficiency of IT processes.

In order the company would be able to overcome various obstacles and risks that are associated with BI, and it would be able to implement the BI solutions and use of all its capabilities in the long term, it would be very important to identify, manage and exploit the key success factors for BI solutions.

\section{IDENTIFICATION AND ANALYSIS OF KEY SUCCESS FACTORS OF IMPLEMENTATION AND USE OF BUSINESS INTELLIGENCE}

The level and success of management BI system are determined by number of internal and external factors of differing importance and intensity of action. Successful implementation and use of BI in enterprises are affected mainly by the most important, so-called key or critical success factors for BI. Several authors and researchers have tried to identify these key success factors for BI, based on their theoretical knowledge and practical experience.

At present, it is possible to find in the literature a lot of efforts to identifying key success factors for BI. Opinions of experts in this area cannot be unified, because of the different knowledge and experience background, but also of the point of view in examining this issue. Overall, however, they present valuable suggestions and instructions concerning the key success factors for BI, which strongly support increasing the efficiency of the whole process of implementation and use of BI in business practice.

The starting point in identifying the key success factors for BI was a study of numerous contributions, publications, independent studies and surveys, as well as our knowledge and experience in this field. In addition, we have consulted and discussed this topic with several experts in the theory and practice of business, who are dealing with this issue. In particular, we have examined common characteristics of organizations that succeed in implementing and using BI, implying the difference between success and failure. We have identified and confirmed some of the most common BI key success factors which are necessary for successful implementation and use of BI. Based on the results of the examination, we have identified seven key success factors of implementation and use of BI in enterprises (Figure 1):

- Active involvement of a strong sponsor respectively of the project.

- BI competence centre.

- High quality of the source data.

- Close cooperation between solution users and the team of 
professional IT staff.

- Enterprise-wide solution scope.

- Corporate culture opened to change.

- Properly selected analytical tools, and promoting active use of available tools.

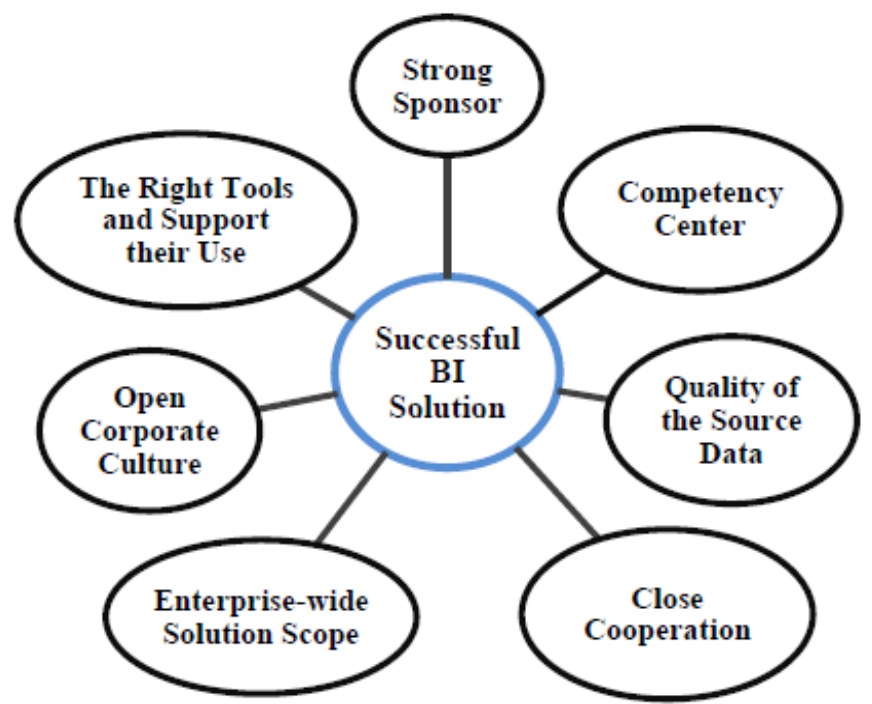

Fig 1. Key Success Factors for the Implementation and Use of BI in Corporate Governance.

Source: own research.

In the case study by Dawson ${ }^{6}$ that was in the South African financial services sector, critical success factors were set as follows: user involvement, data quality, business champion, business case, top management support, business unit strategy, literacy, data classifications, financial resources, time restrictions and other. The survey involved 26 participants who participated in the implementation of $\mathrm{BI}$ in the enterprise. It was the information or business intelligence managers, BI professionals, project managers and other information technology staff. The total sample consisted of 26 respondents who had to choose five key factors. In this study, as importantly, it appeared as follows (Figure 2).

Another point of the survey was rated on a scale from one to five the importance of selected factors that affect the most, while 1 means hardly important and 5 is very important. It was made the average mark. It follows that the most important factor is the quality of information, IT influence on

\footnotetext{
${ }^{6}$ Dawson, L. and Van Belle, J.P., Critical Success Factors for Business Intelligence in the South African Financial Services Sector (SAJIM 2013).
} 


\section{business strategy and user involvement (Figure 3).}

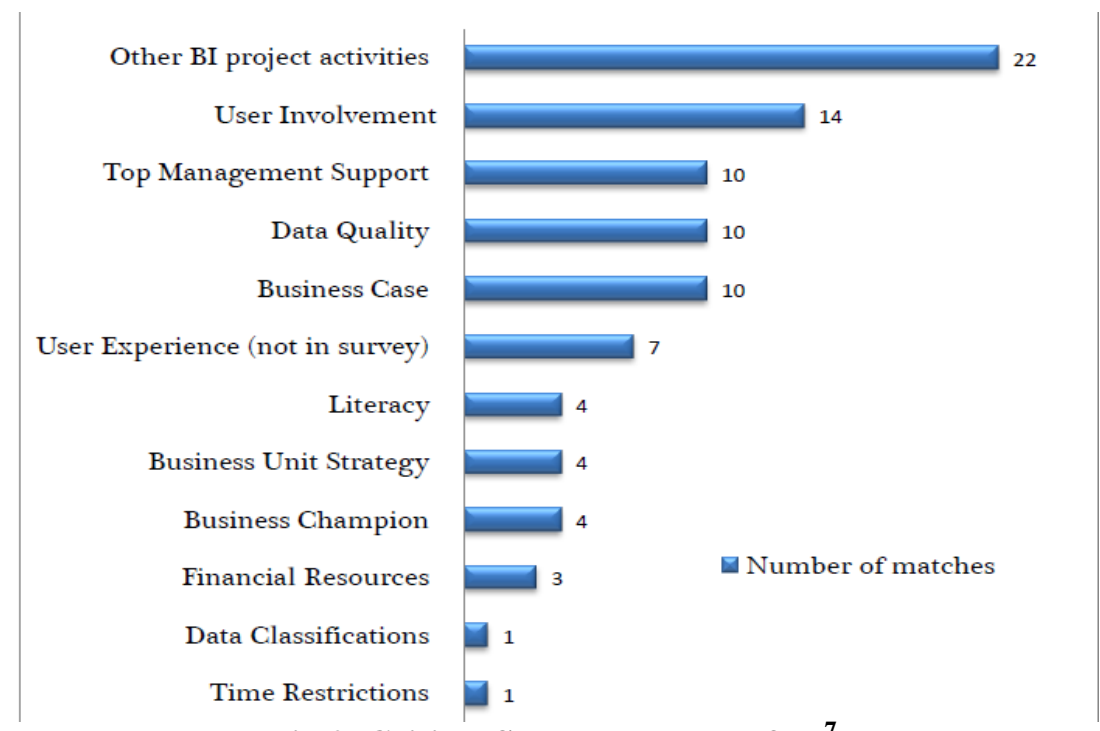

Fig 2. Critical Success Factors of BI ${ }^{7}$.

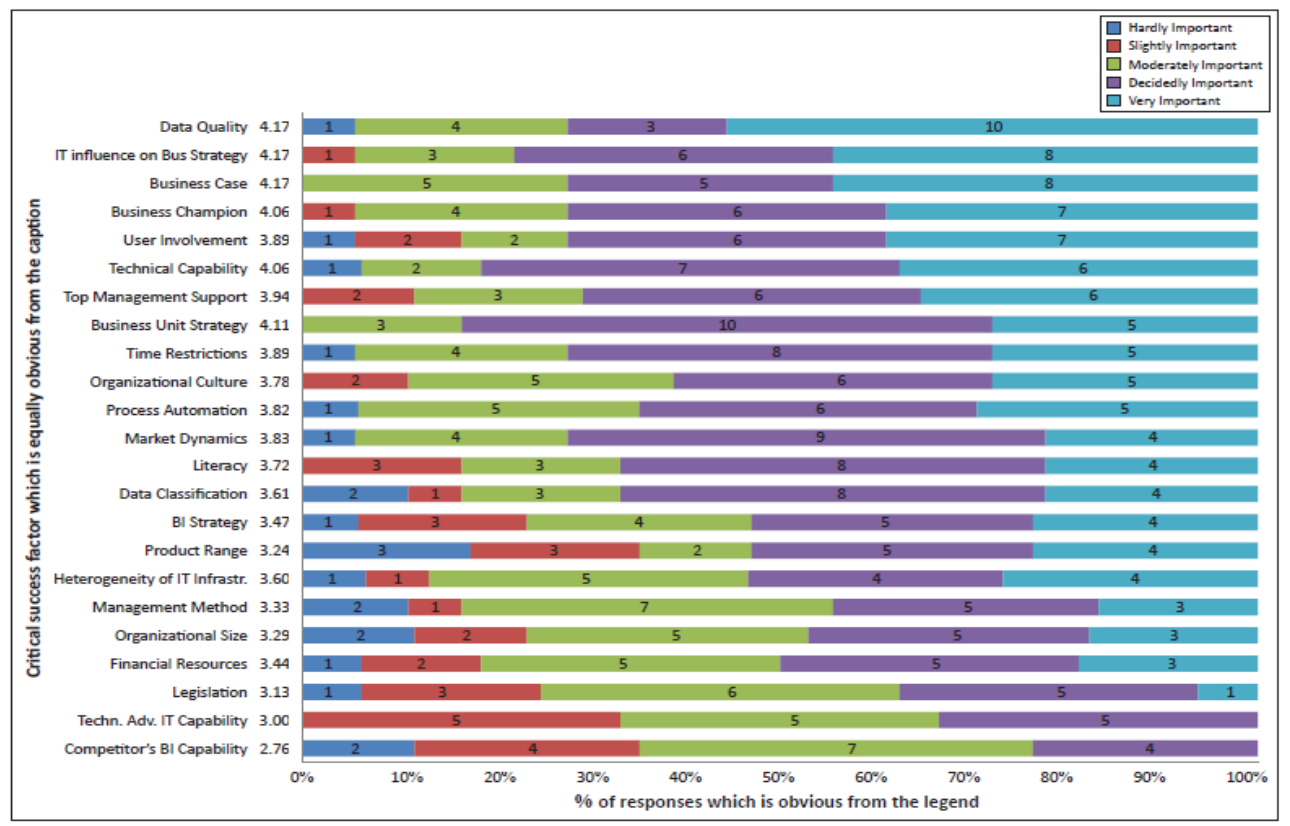

Fig 3. Importance Ratings for Each Critical Success Factor by Average and Detailed Breakdown 8 .

\footnotetext{
${ }^{7}$ Dawson, L. and Van Belle, J.P., Critical Success Factors for Business Intelligence in the South African Financial Services Sector (SAJIM 2013).

${ }^{8}$ Dawson, L. and Van Belle, J.P., Critical Success Factors for Business Intelligence in the South African Financial Services Sector (SAJIM 2013).
} 
These key success factors of BI are not just enough to identify. These factors are also necessary to measure. Respectively measure their impact on the successful implementation and use of BI. Need to analyse key success factors is one of the conditions for the successful use of BI and improvement of efficiency management processes in the company.

One of the factors of success of the $\mathrm{BI}^{9}$ (Eckerson, 2005) is the mutual cooperation between ordinary users of solution and team of professional BI staff. W. Eckerson studied the link between teamwork and success of BI project in his research (see Figure 4). As is apparent from the graph, very good cooperation has been substantially demonstrated to achieve a successful solution. The research results thus confirmed the great importance of this factor and its significant impact on the success of the BI project.

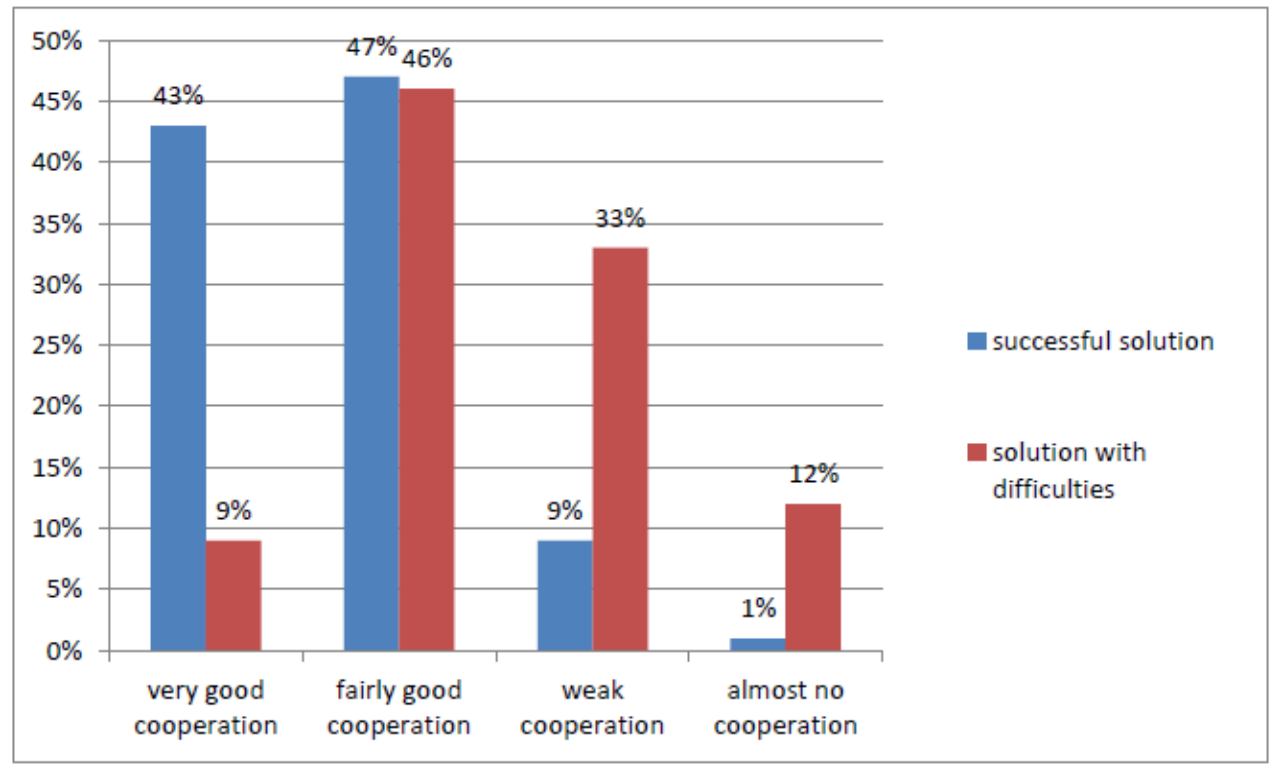

Fig 4. The Connection between Teamwork and Success of BI Project ${ }^{10}$.

Another study points to the positive impact of strong investor in the project. Figure 5 shows that projects involving sponsors are successful.

\footnotetext{
${ }^{9}$ Eckerson, W., Data Quality and the Bottom Line: Achieving Business Success through a Commitment to High Quality Data (2002). Available at http://download.101 com.com/pub/tdwi/Files/DQReport.pdf.

${ }^{10}$ Eckerson, W., Data Quality and the Bottom Line: Achieving Business Success through a Commitment to High Quality Data (2002). Available at http://download.101com.com/pub/tdwi/Files/DQReport.pdf.
} 


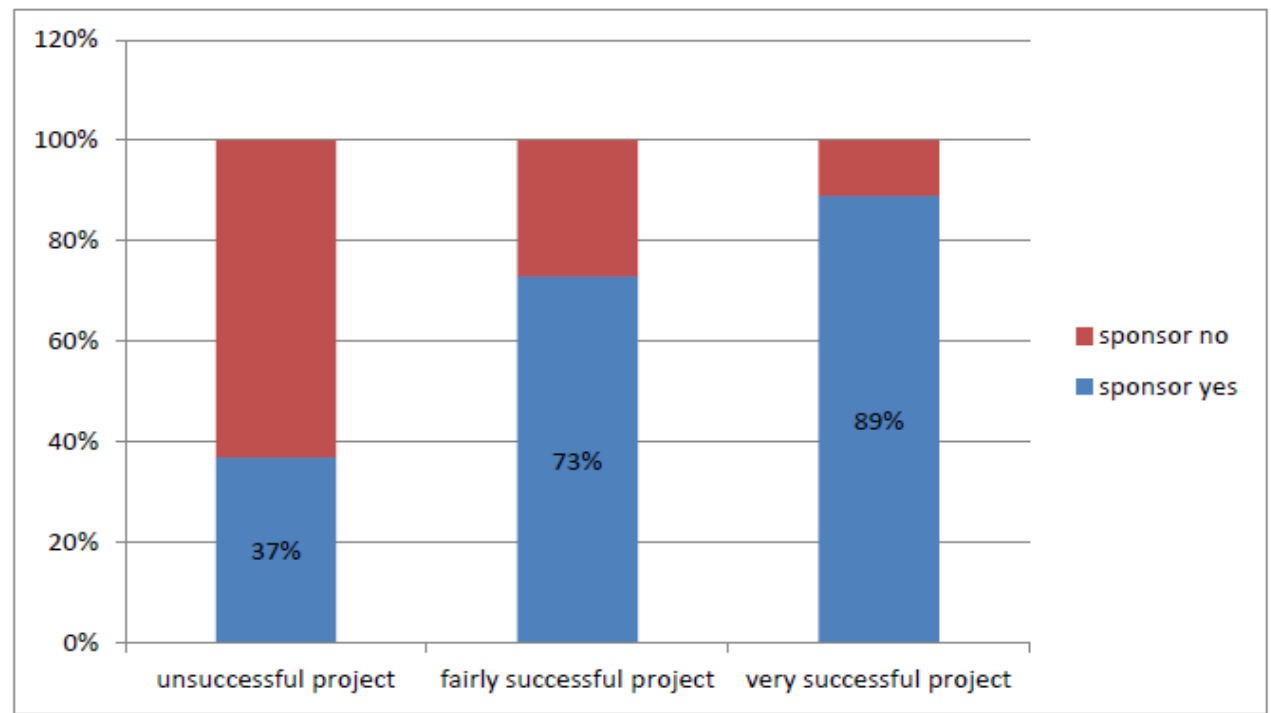

Fig 5. Impact of Sponsor Involvement on the Success of the BI Project.

Howson ${ }^{11}$ in her research also compared the impact of the decisionmaking on the intuition basis and on the results of analyses which were made by BI applications, on the success of BI projects. As is shown in Figure 6, a high percentage (73\%) of successful BI solutions is achieved in process of decision-making that is realised according to the results of data analyses.

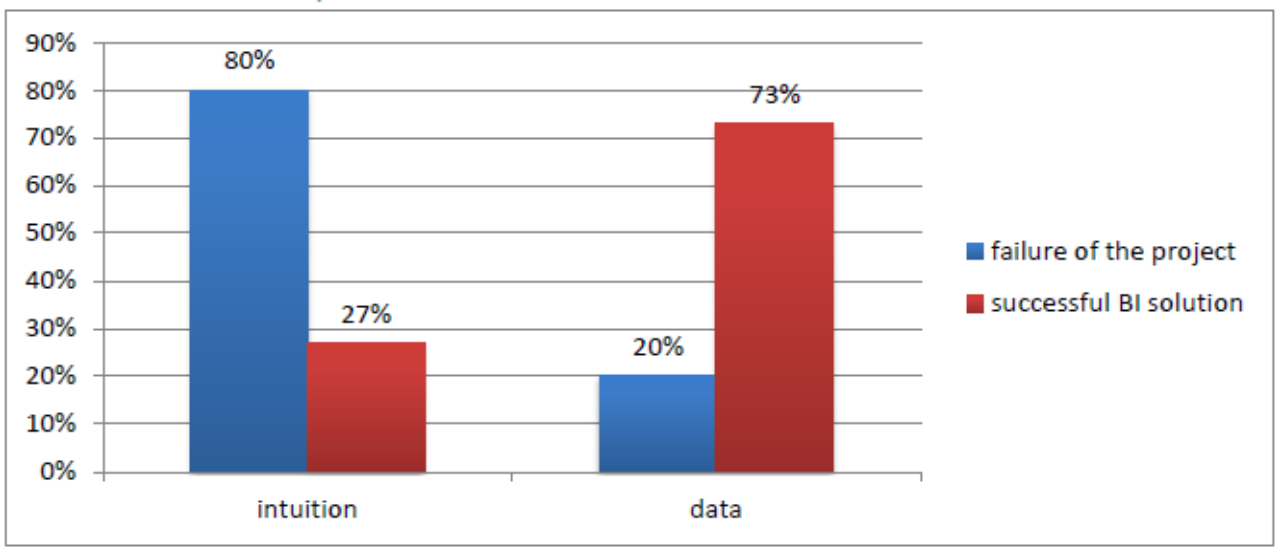

Fig 6. Decision-making Based on Intuition versus the Results of the Analysis of Data $^{12}$.

\footnotetext{
${ }^{11}$ Howson, C., Successful Business Intelligence: SeCREts to Making BI the Killer ApP (New York, McGraw-Hill Companies. ISBN 978-0-07-149851-7, 2008).

${ }^{12}$ Howson, C., Successful Business InTElligence: SeCRETS to Making BI the Killer ApP (New York, McGraw-Hill Companies. ISBN 978-0-07-149851-7, 2008).
} 


\section{KEY FACTORS AND BARRIERS OF BUSINESS 231}

CONCLUSION

The presented overview of factors provides only a general view of the key success factors for BI, which proved some authors in their work. There are a number of other authors who have dealt in the past 10-15 years with this issue and who have defined the most important success factors for BI on the basis of their expertise, experience and research. It is undisputed that BI is beneficial for businesses and it has positive impact on the management of processes in the company. Every BI solution in a particular business is individual. Therefore, the conditions for the adoption and use are diverse and it is possible that a successful factor is not equal for every enterprise. Key factors in the implementation and use of BI are still necessary to find and measure their impact. 